\title{
Síntese e Caracterização Térmica e Química do Copolímero Poli(D,L-lactídeo-co-glicolídeo)
}

\author{
Cynthia D. C. Erbetta, Carla C. B. Viegas, Roberto F. S. Freitas, Ricardo G. Sousa \\ Departamento de Engenharia Química, UFMG
}

\begin{abstract}
Resumo: O copolímero poli(D,L-lactídeo-co-glicolídeo) apresenta-se como um dos polímeros de maior interesse para aplicação na área médica. O fato de ser biorreabsorvível, biocompatível, atóxico e ter uma cinética de degradação que pode ser modificada pela razão entre os monômeros na copolimerização justifica tal interesse. Neste trabalho, os copolímeros foram sintetizados a $175^{\circ} \mathrm{C}$, por meio da abertura dos anéis dos dímeros cíclicos dos monômeros D,L-lactídeo e glicolídeo, na presença do iniciador octanoato de estanho e do co-iniciador álcool laurílico. O controle eficiente do vácuo no meio reacional, aliado à adequada agitação, foram fundamentais para o sucesso da síntese. Para caracterização dos copolímeros sintetizados foram empregadas as técnicas de calorimetria exploratória diferencial (DSC), termogravimetria (TG) e espectroscopia na região do infravermelho (FTIR). Foram analisados não somente os produtos de reação, mas também os monômeros de partida. A nova rota de síntese utilizada mostrou-se adequada, sendo os copolímeros poli(D,L-lactídeo-coglicolídeo) obtidos com sucesso.
\end{abstract}

Palavras-chave: PLGA, poli(D,L-lactídeo-co-glicolídeo), biopolímero, síntese, caracterização, DSC, TG, FTIR.

\section{Synthesis and Thermal and Chemical Characterization of the Poly(D,L-lactide-co-glycolide) Copolymer}

\begin{abstract}
Poly (D, L-lactide-co-glycolide) copolymer (PLGA) has attracted a great deal of interest due to their special characteristics as biomaterials since it is bioreabsorbable, biocompatible, nontoxic and the kinetics of degradation can be modified by the ratio of monomers in copolymerization. In this work, the copolymers were synthesized at $175{ }^{\circ} \mathrm{C}$, by opening the ring of cyclic dimers of D,L-lactide and glycolide monomers in the presence of tin(II) octanoate initiator and lauryl alcohol co-initiator. The efficient control of the vacuum in the medium combined with adequate stirring were essential to the success of the synthesis. Characterization of the copolymers samples was carried out by using differential scanning calorimetry (DSC), thermogravimetry (TG) and Fourier transform infrared spectroscopy (FTIR). We analyzed not only the products of reaction but also the initial monomers. The new synthesis route employed was appropriate and the poly(D, L-lactide-co-glycolide) was successfully obtained.
\end{abstract}

Keywords: PLGA, poly(D,L-lactide-co-glycolide), biopolymer, synthesis, characterization, DSC, TG, FTIR.

\section{Introdução}

Até 1960, polímeros hidroliticamente instáveis eram considerados indesejáveis. Entretanto, com o avanço das pesquisas, esses materiais passaram a despertar o interesse nas áreas médica e farmacêutica, especialmente devido à possibilidade de serem utilizados em implantes temporários (suturas, grampos, nanoreservatórios para fármacos, etc. ${ }^{[1]}$. O poli(lactídeo) (PLA) e o poli(lactídeo-co-glicolídeo) (PLGA) são poliésteres relativamente hidrofóbicos, instáveis em condições úmidas e biodegradáveis a subprodutos atóxicos (ácido lático, ácido glicólico, dióxido de carbono e água) ${ }^{[2]}$. Os polímeros derivados dos ácidos lático e glicólico têm recebido muita atenção nas pesquisas de polímeros biodegradáveis alternativos, existindo diversos estudos demonstrando sua baixa toxicidade, inclusive com aprovação pelo "Food and Drug Administration" (FDA) para a utilização como sistemas de liberação de fármacos (DDS) ${ }^{[3]}$.

Os copolímeros de PLGA são formados por unidades de monômeros de lactídeo e glicolídeo. Possuem propriedades desejáveis como taxa constante de biodegradação, morfologia, resistência mecânica e geometria regular de cadeias individuais ${ }^{[4-6]}$.

O lactídeo é mais hidrofóbico que o glicolídeo, portanto copolímeros de PLGA ricos em lactídeo são menos hidrofílicos, absorvem, pois, menos água e degradam mais lentamente ${ }^{[4]}$. É importante salientar que a relação entre a razão de glicolídeo e lactídeo, com as propriedades físico-químicas do correspondente copolímero, não é linear. Embora o poli(glicolídeo) (PGA) seja altamente cristalino, a cristalinidade é rapidamente perdida em copolímeros de lactídeo e glicolídeo. Essas mudanças morfológicas levam a um incremento na taxa de hidratação e de hidrólise ${ }^{[7]}$.

O glicolídeo é muito mais reativo que o D,L-lactídeo. Isso leva à formação de copolímeros com sequência de blocos ao longo da cadeia $^{[8]}$. Inclusão de glicolídeo na cadeia do poli(lactídeo) altera a cristalinidade, solubilidade, taxa de biodegradação e absorção de água pelo polímero ${ }^{[9]}$. O glicolídeo, pelo fato de apresentar reatividade maior que o lactídeo, é normalmente encontrado no polímero final em uma maior proporção que aquela em que foi adicionado na mistura de monômeros, antes do início da reação ${ }^{[10]}$.

A copolimerização do PLGA pode ser realizada basicamente por dois caminhos: 1) reação de policondensação direta do ácido lático e do ácido glicólico, obtendo-se copolímeros de baixa massa molar ${ }^{[11,12] ; 2)}$ polimerização via abertura dos dímeros cíclicos do ácido lático (lactídeo) e do ácido glicólico (glicolídeo), resultando em copolímeros de alta massa molar e, consequentemente, melhores propriedades mecânicas ${ }^{[8,10,13,14]}$. A polimerização em massa geralmente ocorre por um período de 2 a 6 horas, sob temperatura em torno de $175^{\circ} \mathrm{C}$, na presença de iniciador. Durante o processo, pode ser adicionado álcool laurílico para controlar a massa molar ${ }^{[15]}$.

O lactídeo possui um carbono beta assimétrico que permite a obtenção das formas levógira (L-PLA), dextrógira (D-PLA) ou racêmica (D,L-PLA), sendo as formas levógira e dextrógira 
semicristalinas e a forma racêmica amorfa ${ }^{[16]}$. Em sistemas de liberação de fármacos, o D,L-PLA é mais utilizado, pois permite uma dispersão mais homogênea do fármaco no copolímero ${ }^{[17]}$. $\mathrm{Na}$ produção de sistemas para aplicações médicas, usa-se o 2-etil-hexanoato de estanho (II), abreviado como octanoato de estanho $\left[\mathrm{Sn}(\mathrm{Oct})_{2}\right]$, como iniciador da polimerização ${ }^{[8]}$.

O presente trabalho teve como objetivo estudar uma nova rota de síntese do copolímero PLGA, bem como sua caracterização térmica e química. Essa nova rota consistiu, pela primeira vez, da copolimerização em massa dos monômeros D,L-lactídeo e glicolídeo à temperatura de $175^{\circ} \mathrm{C}$, com o iniciador 2-etil-hexanoato de estanho e o co-iniciador álcool laurílico, além da aplicação de vácuo no meio reacional.

\section{Experimental}

\section{Síntese do copolímero PLGA}

O copolímero PLGA foi sintetizado via polimerização em massa, por meio da abertura dos anéis dos diésteres cíclicos de seus monômeros (D,L-lactídeo e glicolídeo). Variáveis como proporção (em massa) do iniciador octanoato de estanho $(0,02 \%$ sobre a massa total de monômeros) e de co-iniciador álcool laurílico $(0,01 \%$ sobre a massa total de monômeros) foram escolhidas com base em um estudo realizado por Kiremitçi-Gümüsderelioglu e Deniz ${ }^{[18]}$. Para as outras variáveis do processo como tempo de reação ( 2 horas) e temperatura $\left(175{ }^{\circ} \mathrm{C}\right)$, utilizou-se como referência o estudo de Bendix $^{[8]}$

A reação de copolimerização é ilustrada pela Figura $1^{[18]}$.

As razões entre os monômeros empregadas nas sínteses escolhidas foram: 70/30 e 50/50, expressas entre a proporção de D,L-lactídeo e glicolídeo (em massa). Tal escolha foi baseada na literatura ${ }^{[15]}$, em função do tempo de degradação desses copolímeros. Essas razões são as mais aplicadas em sistemas de liberação controlada de fármacos.

Foram realizadas 4 sínteses, sendo 2 delas na proporção 70/30 e as outras 2 na proporção 50/50, utilizando frasco de vidro e rolha de borracha, sob vácuo e com agitação magnética. Todas as sínteses foram realizadas à temperatura de $175{ }^{\circ} \mathrm{C}$ por 2 horas, utilizando banho de óleo de silicone. Para controle da temperatura utilizou-se placa aquecedora e agitador magnético (Fisatom/752A). A variação de temperatura verificada no banho de silicone foi de $\pm 5{ }^{\circ} \mathrm{C}$.

Todo o material empregado na pesagem, síntese e purificação do copolímero, foi previamente lavado, secado e mantido em dessecador a vácuo (J. Prolab) por, no mínimo, 24 horas antes do uso, a fim de minimizar a presença de umidade durante o processo. Os monômeros D,L-lactídeo e glicolídeo foram adquiridos da Sigma-Aldrich, juntamente com o iniciador, octanoato de estanho. Os demais reagentes, álcool laurílico, óleo de silicone, metanol PA anidro e cloreto de metileno PA anidro, foram adquiridos da Vetec. Todos foram usados como adquiridos, ou seja, sem purificação prévia. Somente os monômeros foram acondicionados em geladeira, os demais, armazenados em condição ambiente.

Ao final das sínteses, o copolímero PLGA foi dissolvido em cloreto de metileno anidro e precipitado em metanol anidro, em excesso. Em seguida, o material foi submetido ao processo de secagem, entre 60 e $70{ }^{\circ} \mathrm{C}$ sob vácuo $(-60 \mathrm{cmHg})$ por, no mínimo, 48 horas em estufa (Vacuoterm/6030A), para remoção de solventes residuais.

Após secagem, o copolímero foi moído, utilizando moinho de bolas (Stoneware) em rotação máxima de $100 \mathrm{rpm}$ por, no mínimo, 24 horas. O PLGA moído foi peneirado em peneira de 24 mesh e acondicionado em frasco de vidro, na geladeira $\left(2\right.$ a $\left.5{ }^{\circ} \mathrm{C}\right)$.

\section{Caracterização do copolímero PLGA}

\section{Análise por calorimetria exploratória diferencial (DSC)}

O equipamento de DSC utilizado, um Schimadzu modelo DSC50 , foi programado primeiramente para aquecimento das amostras, da temperatura ambiente $\left( \pm 20{ }^{\circ} \mathrm{C}\right)$ a $120{ }^{\circ} \mathrm{C}$, a uma razão de $10{ }^{\circ} \mathrm{C} / \mathrm{min}$ ( $1^{\mathrm{a}}$ corrida), a fim de se apagar a história térmica do material. O cadinho utilizado foi de alumínio não selado e o gás de arraste, nitrogênio, a uma vazão de $20 \mathrm{~mL} / \mathrm{min}$. A massa das amostras analisadas variou entre 5 e $10 \mathrm{mg}$. Ao final da primeira corrida, resfriou-se o forno do calorímetro com nitrogênio líquido até a temperatura de $-30{ }^{\circ} \mathrm{C}$. Em seguida, o equipamento foi programado para uma nova corrida até $300{ }^{\circ} \mathrm{C}$ a uma razão de aquecimento de $5{ }^{\circ} \mathrm{C} / \mathrm{min}$. A temperatura de transição vítrea $\left(\mathrm{T}_{\mathrm{g}}\right)$ foi determinada na segunda análise. Para os monômeros D,L-lactídeo e glicolídeo determinou-se a temperatura de fusão $\left(\mathrm{T}_{\mathrm{m}}\right)$. Já para os copolímeros de PLGA foi possível verificar a temperatura de degradação $\left(\mathrm{T}_{\mathrm{d}}\right)$.

\section{Análise por termogravimetria (TG)}

A análise por termogravimetria foi realizada a uma razão de aquecimento de $10{ }^{\circ} \mathrm{C} / \mathrm{min}$, da temperatura ambiente $\left( \pm 20^{\circ} \mathrm{C}\right)$ até $400{ }^{\circ} \mathrm{C}$, em cadinho de platina não selado e atmosfera de nitrogênio a uma vazão de $20 \mathrm{~mL} / \mathrm{min}$. O equipamento empregado foi um Schimadzu modelo TGA-50. A massa das amostras analisadas variou entre 5 e $10 \mathrm{mg}$. Por meio dessa técnica, foi possível determinar a temperatura de início da degradação térmica e a variação de massa em função do aumento da temperatura. Utilizou-se a termogravimetria derivada para identificar a temperatura de máxima degradação ( $\left.\mathrm{T}_{\text {deg.máx. }}\right)$, ou seja, a temperatura do pico da curva DTG.

\section{Análise por espectroscopia na região do infravermelho (FTIR)}

Os espectros de absorção na região do infravermelho para os monômeros e copolímeros, na faixa de 4000 a $650 \mathrm{~cm}^{-1}$, foram obtidos em espectrofotômetro FTIR Spectrum one (Perkin Elmer), no modo ATR, com 4 varreduras, resolução de $4 \mathrm{~cm}^{-1}$ e amostra na forma de pó. Os espectros foram obtidos à temperatura ambiente $\left( \pm 20^{\circ} \mathrm{C}\right)$ com posicionamento direto da amostra sobre o cristal do aparelho, sem tratamento prévio.

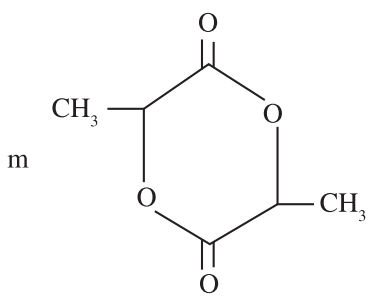

Lactídeo

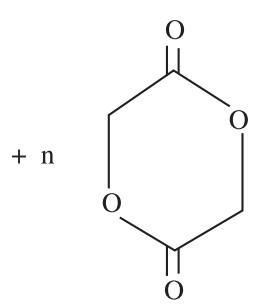

Glicolídeo

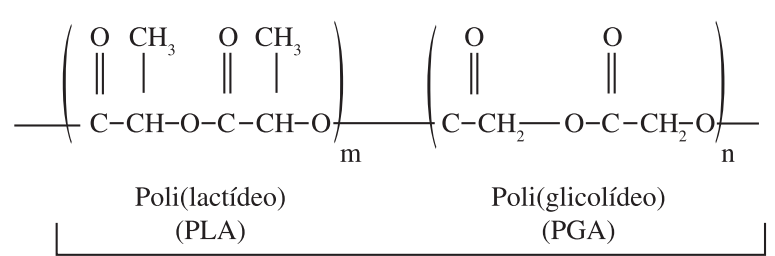

PLGA

Figura 1. Estruturas químicas dos dímeros e polímeros e reação de copolimerização ${ }^{[18]}$. 


\section{Resultados e Discussão}

Logo no início da síntese, observou-se a fusão do glicolídeo, ocupando assim a parte inferior do frasco reacional, enquanto que o outro monômero, D,L-lactídeo, apresentava-se parcialmente insolúvel e suspenso sobre o glicolídeo fundido. Desta forma, caso não se tenha uma agitação eficiente pode-se propiciar a polimerização preferencial do glicolídeo ou a formação de copolímero em bloco, uma vez que existem condições favoráveis para que isso ocorra, quais sejam: elevada temperatura de síntese, presença de iniciador e o fato do glicolídeo ter maior reatividade do que o D,L-lactídeo. Outro ponto importante a se considerar diz respeito ao vácuo, uma vez que o mesmo evita a presença de umidade no meio reacional, extremamente prejudicial à copolimerização ${ }^{[8,15,19]}$, e a elevação da pressão no sistema devido à evaporação do monômero D,L-lactídeo. Com a evaporação do D,L-lactídeo a pressão interna do frasco reacional (sistema fechado) aumenta, favorecendo sua condensação e reincorporação na síntese.

Notou-se que copolímeros de maior proporção de glicolídeo em sua estrutura são menos solúveis, necessitando assim de um maior volume de solvente para completa dissolução.

A Figura 2 apresenta as curvas DSC dos monômeros D,Llactídeo e glicolídeo.

Pela Figura 2, pode-se notar o primeiro evento térmico (pico endotérmico) das curvas DSC representativo da fusão dos monômeros glicolídeo e D,L-latídeo, respectivamente. Para o D,Llactídeo, o segundo pico endotérmico caracteriza a evaporação do monômero, também identificado na caracterização térmica realizada por Jabbari e Xuezhong ${ }^{[20]}$. No caso do glicolídeo, tanto o segundo quanto o terceiro pico, acredita-se ser referente à degradação do monômero (eventos endotérmicos), uma vez que o glicolídeo não apresenta ponto de ebulição.

A Figura 3 apresenta as curvas DSC dos copolímeros sintetizados.

Pelas curvas DSC (Figura 3), foi possível observar as transições térmicas relacionadas com a transição vítrea (mudança de inclinação da linha de base da curva DSC) e com a degradação das cadeias poliméricas (pico endotérmico da curva DSC). Percebe-se também nessas curvas, a ausência de evento de transição de fase referente à fusão. Com isso, pode-se inferir que todos os copolímeros analisados tratam-se de polímeros amorfos, o que está de acordo com a literatura. Copolímeros PLGA contendo menos que $85 \%$ de glicolídeo são amorfos ${ }^{[21]}$.

Os resultados das análises por DSC encontram-se resumidos na Tabela 1. Esta tabela mostra as temperaturas de transição vítrea $\left(\mathrm{T}_{\mathrm{g}}\right)$ e de degradação $\left(\mathrm{T}_{\mathrm{d}}\right)$ dos copolímeros de PLGA obtidos a partír das curvas de DSC ( $2^{\circ}$ aquecimento) dessas amostras. Para os monômeros foram relacionadas as temperaturas de fusão $\left(\mathrm{T}_{\mathrm{m}}\right)$, de evaporação e de degradação, também a partir do $2^{\circ}$ aquecimento das respectivas amostras. As $\mathrm{T}_{\mathrm{g}_{\mathrm{s}}}$ indicadas na Tabela 1 foram determinadas diretamente pelo software do equipamento e as $\mathrm{T}_{\mathrm{d} \text { 's }} \mathrm{e}$ $\mathrm{T}_{\mathrm{m} \text { 's }}$ referem-se aos picos endotérmicos das curvas DSC.

$\mathrm{Na}$ Tabela 1, não constam os valores da variação de entalpia $\left(\Delta \mathrm{H}_{\mathrm{d}}\right)$ do pico correspondente à degradação das amostras das sínteses 1 e 2 , pois o evento endotérmico foi finalizado a $300^{\circ} \mathrm{C}$. Tal temperatura é uma limitante do forno empregado.

Comparando-se as curvas obtidas no presente estudo (Figura 3), com as curvas DSC, TG/DTG para o copolímero D,L-PLGA (50/50), publicadas por Silva Junior et al. ${ }^{[22]}$, percebe-se o mesmo comportamento, qual seja, a transição vítrea e a degradação desses polímeros. A única diferença foi que tanto a transição vítrea quanto a degradação ocorreram em temperaturas menores do que as apresentadas na literatura $\left(46-52^{\circ} \mathrm{Ce} 309-381^{\circ} \mathrm{C}\right.$, respectivamente). Uma possível explicação para tal fato estaria relacionada à massa molar do copolímero. Polímeros com menor massa molar degradam mais rapidamente do que aqueles com maior massa molar ${ }^{[23]}$.

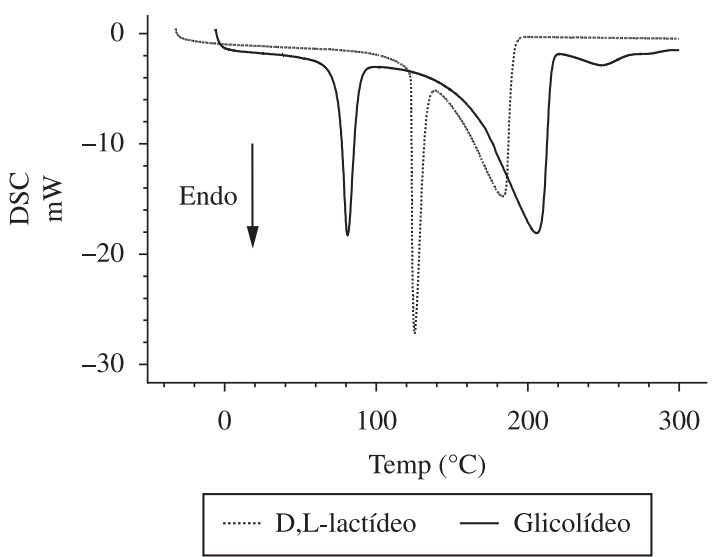

Figura 2. Curvas DSC para os monômeros D,L-lactídeo e glicolídeo ( $2^{\circ}$ aquecimento). Razão de aquecimento de $10{ }^{\circ} \mathrm{C} / \mathrm{min}$ de -25 até $300{ }^{\circ} \mathrm{C}$.

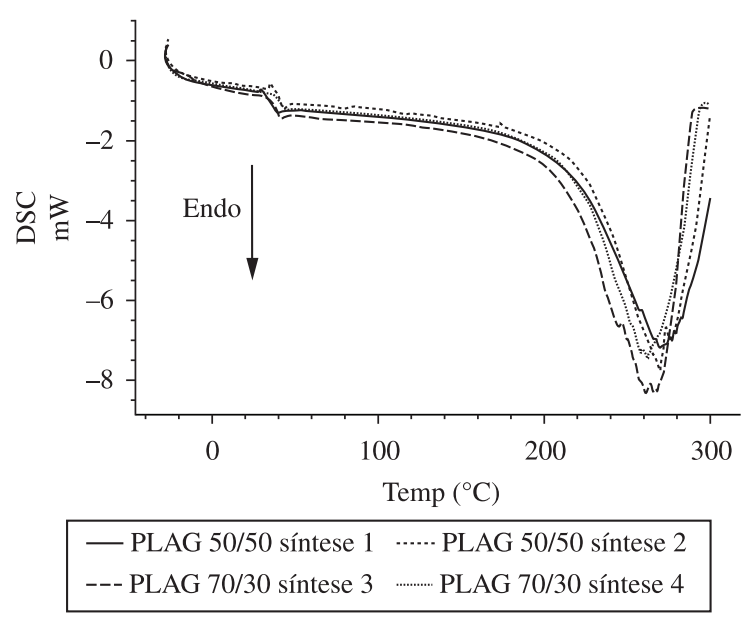

Figura 3. Curvas DSC para os copolímeros PLGA 50/50 (sínteses 1 e 2) e PLGA 70/30 (sínteses 3 e 4). Razão de aquecimento de $5{ }^{\circ} \mathrm{C} / \mathrm{min}$ de -25 até $300{ }^{\circ} \mathrm{C}$.

Tabela 1. Propriedades térmicas dos monômeros e copolímeros por DSC.

\begin{tabular}{cccccc}
\hline Amostra & $\begin{array}{c}\mathbf{T}_{\mathrm{g}} \\
\left({ }^{\circ} \mathbf{C}\right)\end{array}$ & $\begin{array}{c}\mathbf{T}_{\mathrm{m}} \\
\left({ }^{\circ} \mathbf{C}\right)\end{array}$ & $\begin{array}{c}\Delta \mathbf{H}_{\mathrm{f}} \\
\left(\mathbf{J J}^{-1}\right)\end{array}$ & $\begin{array}{c}\mathbf{T}_{\mathbf{d}} \\
\left({ }^{\circ} \mathbf{C}\right)\end{array}$ & $\begin{array}{c}\Delta \mathbf{H}_{\mathrm{d}} \\
\left(\mathbf{J J}^{-1}\right)\end{array}$ \\
\hline D,L-lactí́deo & N/A & 125 & -116 & $183^{*}$ & $-262^{*}$ \\
Glicolídeo & N/A & 81 & -98 & 206 & -415 \\
PLGA 50/50 síntese 1 & 35 & N/A & N/A & 270 & - \\
PLGA 50/50 síntese 2 & 40 & N/A & N/A & 270 & - \\
PLGA 70/30 síntese 3 & 38 & N/A & N/A & 261 & -559 \\
PLGA 70/30 síntese 4 & 39 & N/A & N/A & 262 & -535 \\
\hline
\end{tabular}

*Refere-se à evaporação do monômero D,L-lactídeo e não degradação; N/A $\equiv$ Não se aplica.

As Figuras 4 e 5 mostram as curvas de termogravimetria e sua derivada para os monômeros D,L-lactídeo e glicolídeo, bem como para os copolímeros sintetizados. As curvas apresentadas nestas figuras representam a perda de massa (em \%) e a derivada desta perda (DTG) em função da temperatura $\left(\mathrm{em}{ }^{\circ} \mathrm{C}\right)$.

Os resultados das análises de TG para monômeros e copolímeros encontram-se resumidos na Tabela 2. Os valores de $\mathrm{T}_{\text {onset }}$ e $\mathrm{T}_{\text {endset }}$ (temperatura inicial e final de perda de massa, respectivamente) foram retirados da curva $\mathrm{TG}$ e os resultados de $\mathrm{T}_{\text {deg.máx. }}$ (temperatura onde a perda de massa é máxima) da curva DTG (DrTGA) dos respectivos copolímeros. 


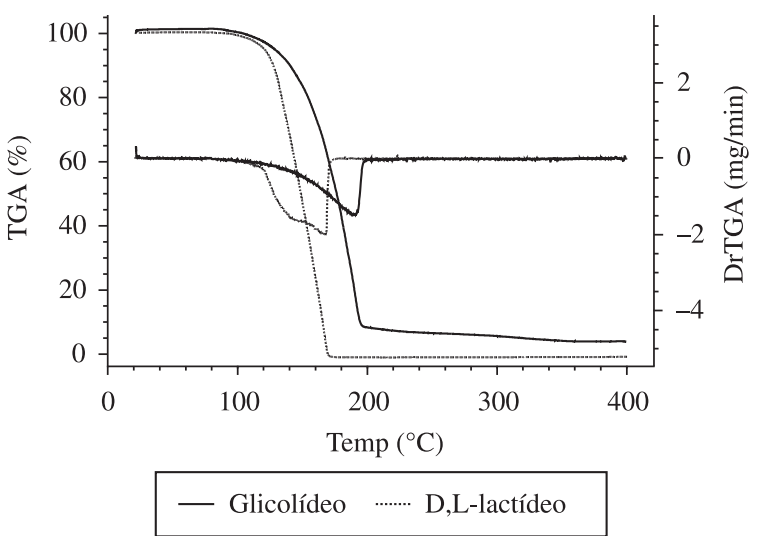

Figura 4. Curvas TG dos monômeros D,L-lactídeo e glicolídeo. Razão de aquecimento de $10{ }^{\circ} \mathrm{C} / \mathrm{min}$ de 20 a $400{ }^{\circ} \mathrm{C}$.

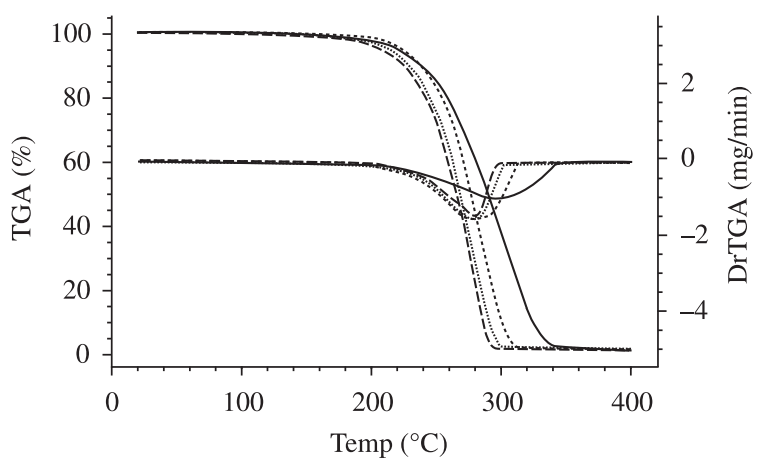

$$
\begin{array}{lll}
\text { - PLGA 50/50 síntese } 1 & \text {..... PLGA 50/50 síntese } 2 \\
\text {--. PLGA 70/30 síntese } 3 & \text { …… PLGA 70/30 síntese } 4
\end{array}
$$

Figura 5. Curvas TG e DTG para os copolímeros PLGA 50/50 (sínteses 1 e 2) e PLGA 70/30 (sínteses 3 e 4). Razão de aquecimento de $10{ }^{\circ} \mathrm{C} / \mathrm{min}$ de 20 a $400{ }^{\circ} \mathrm{C}$.

Tabela 2. Propriedades térmicas dos monômeros e copolímeros por TG.

\begin{tabular}{ccccc}
\hline Amostra & $\begin{array}{c}\text { Perda de massa } \\
(\boldsymbol{\%})\end{array}$ & $\begin{array}{c}\mathbf{T}_{\text {onset }} \\
\left({ }^{\circ} \mathbf{C}\right)\end{array}$ & $\begin{array}{c}\mathbf{T}_{\text {deg.máx }} \\
\left({ }^{\circ} \mathbf{C}\right)\end{array}$ & $\begin{array}{c}\mathbf{T}_{\text {endset }} \\
\left({ }^{\circ} \mathbf{C}\right)\end{array}$ \\
\hline D,L-lactídeo & 100 & 137 & $168^{*}$ & 169 \\
Glicolídeo & 97 & 161 & 189 & 195 \\
PLGA 50/50 síntese 1 & 100 & 252 & 300 & 325 \\
PLGA 50/50 síntese 2 & 100 & 253 & 289 & 305 \\
PLGA 70/30 síntese 3 & 100 & 246 & 276 & 291 \\
PLGA 70/30 síntese 4 & 100 & 247 & 279 & 295 \\
\hline
\end{tabular}

*Refere-se à evaporação.

Para todas as amostras do copolímero percebe-se apenas um evento de perda de massa (estágio único). As amostras de PLGA degradam-se totalmente ( $100 \%$ de perda).

Os resultados de termogravimetria apresentados indicam que os copolímeros sintetizados são termicamente estáveis até $240{ }^{\circ} \mathrm{C}$, uma vez que a menor temperatura em que se iniciou o processo de degradação da cadeia polimérica foi de 246 e $247^{\circ} \mathrm{C}$ (PLGA 70/30 - sínteses 3 e 4, respectivamente).

Comparando-se as Tmáx.deg, dos copolímeros, obtidas a partir das curvas DTG, com as $\mathrm{T}_{\mathrm{d}^{\prime} \mathrm{s}}$, determinadas pelas curvas DSC (Tabela 1), percebe-se que elas estão entre 260 e $300{ }^{\circ} \mathrm{C}$, aproximadamente. Além disso, pode-se ver que as Tmáx.deg,s. são maiores que as $\mathrm{T}_{\mathrm{d} \text { 's }}$ para cada copolímero, porém isso era esperado, uma vez que a razão de aquecimento nos ensaios de TG $\left(10{ }^{\circ} \mathrm{C} /\right.$ $\min )$ foi maior do que a utilizada nos ensaios de DSC $\left(5^{\circ} \mathrm{C} / \mathrm{min}\right.$ $2^{\mathrm{a}}$ corrida).

Em comparação com os resultados de termogravimetria publicados na literatura ${ }^{[22]}$, os polímeros sintetizados neste estudo apresentaram comportamento de perda de massa semelhante, porém menores temperaturas de início de degradação térmica, da mesma forma quando se comparou com os resultados de DSC.

Os resultados de DSC e TG indicam a ausência de monômeros residuais nos copolímeros pois, em caso contrário, ter-se-ia nas curvas DSC dos copolímeros a presença de um evento endotérmico característico de fusão e nas curvas TG, a presença de dois eventos de perda de massa bem distintos. Porém, somente com o auxílio de outras técnicas analíticas é que se pode chegar a uma conclusão de fato sobre a ausência de monômeros residuais não reagidos nos copolímeros sintetizados.

Os monômeros, os copolímeros sintetizados e algumas amostras da mistura de PLGA com monômeros (para pesquisa de monômero residual), foram caracterizados estruturalmente por meio de FTIR.

$\mathrm{Na}$ Figura 6 são apresentados os espectros referentes aos copolímeros sintetizados.

Nos espectros dos copolímeros de PLGA pode-se observar fortes bandas na região entre 1750 e $1740 \mathrm{~cm}^{-1}$, característica do estiramento da carbonila $(\mathrm{C}=\mathrm{O})$. Bandas características do estiramento referentes ao grupo (C-O) foram observadas entre 1300 e $1150 \mathrm{~cm}^{-1}$. Foram identificadas também as seguintes bandas de absorção: entre 3000 e $2900 \mathrm{~cm}^{-1}$ características do estiramento dos grupos $\left(\mathrm{CH}, \mathrm{CH}_{3}\right.$ e $\left.\mathrm{CH}_{2}\right)$; entre 1500 e $1250 \mathrm{~cm}^{-1}$ características da deformação dos grupos $\left(\mathrm{CH}_{3}\right.$ e $\left.\mathrm{CH}_{2}\right)$; entre 1350 e $1150 \mathrm{~cm}^{-1}$ características de vibrações do "tipo wag" dos grupos $\left(\mathrm{CH}_{2} \mathrm{e} \mathrm{CH}\right)$. Os copolímeros sintetizados neste estudo não apresentaram bandas de absorção entre 3700 e $3100 \mathrm{~cm}^{-1}$, característica de grupamento $\mathrm{OH}$, indicando ausência de umidade nas amostras. Todas essas bandas de absorção estão em conformidade com a literatura ${ }^{(24)}$.

Comparando os espectros obtidos para os copolímeros sintetizados neste trabalho com o obtido por Hummel ${ }^{[25]}$, observa-se grande similaridade entre eles. Desta forma, pode-se inferir que os resultados obtidos para as análises de FTIR estão de acordo com a literatura. Nota-se uma banda entre 3400 e $3600 \mathrm{~cm}^{-1}$ no espectro desta literatura, característica de grupo $\mathrm{OH}$, ausente nos espectros encontrados nesta pesquisa. Essa banda descrita na literatura, talvez pode ser devido à presença de umidade na amostra, de solvente residual, de monômero glicolídeo não reagido, do sobretom da carbonila (banda muito intensa a $\pm 1745 \mathrm{~cm}^{-1}$ ) ou da absorção de $(\mathrm{OH})$ do grupo carboxila resultante da hidrólise do monômero.

Esses resultados de FTIR corroboram os resultados de DSC e TG no sentido de que os copolímeros de PLGA foram realmente sintetizados com sucesso.

$\mathrm{Na}$ tentativa de empregar a análise por FTIR para detetar presença de monômeros residuais não reagidos, preparou-se algumas amostras de PLGA 70/30 misturadas com pequenas quantidades de monômeros, nas seguintes proporções: $0,5 \%$ de D,L-lactídeo, 0,5\% de glicolídeo e 3\% de glicolídeo (em massa). A escolha destas proporções foi orientada pela informação de que a polimerização via abertura dos anéis gera polímeros com cerca de 1 a $3 \%$ de monômeros residuais, segundo Middleton e Tipton ${ }^{[26]}$.

As Figuras 7-9 apresentam, respectivamente, os espectros do copolímero PLGA 70/30 misturado com $0,5 \%$ do monômero D,L-lactídeo, do monômero D,L-lactídeo puro e do copolímero PLGA 70/30 puro.

Avaliando o espectro apresentado na Figura 7, pode-se observar uma banda de absorção em $935 \mathrm{~cm}^{-1}$ que não está presente no espectro da Figura 9, bem como nos espectros da Figura 6. É 


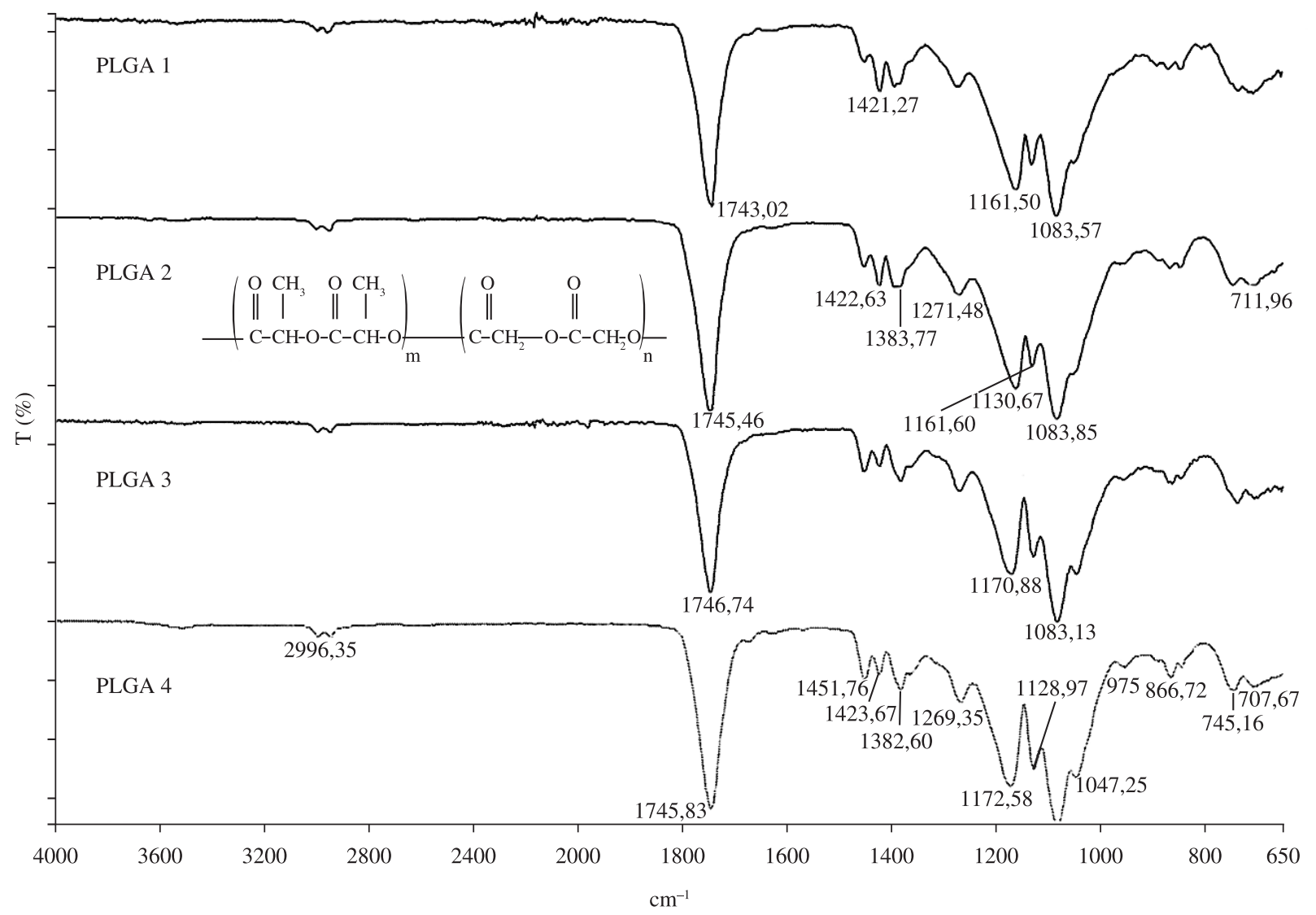

Figura 6. Espectros FTIR para PLGA 50/50 (sínteses 1 e 2) e PLGA 70/30 (sínteses 3 e 4).

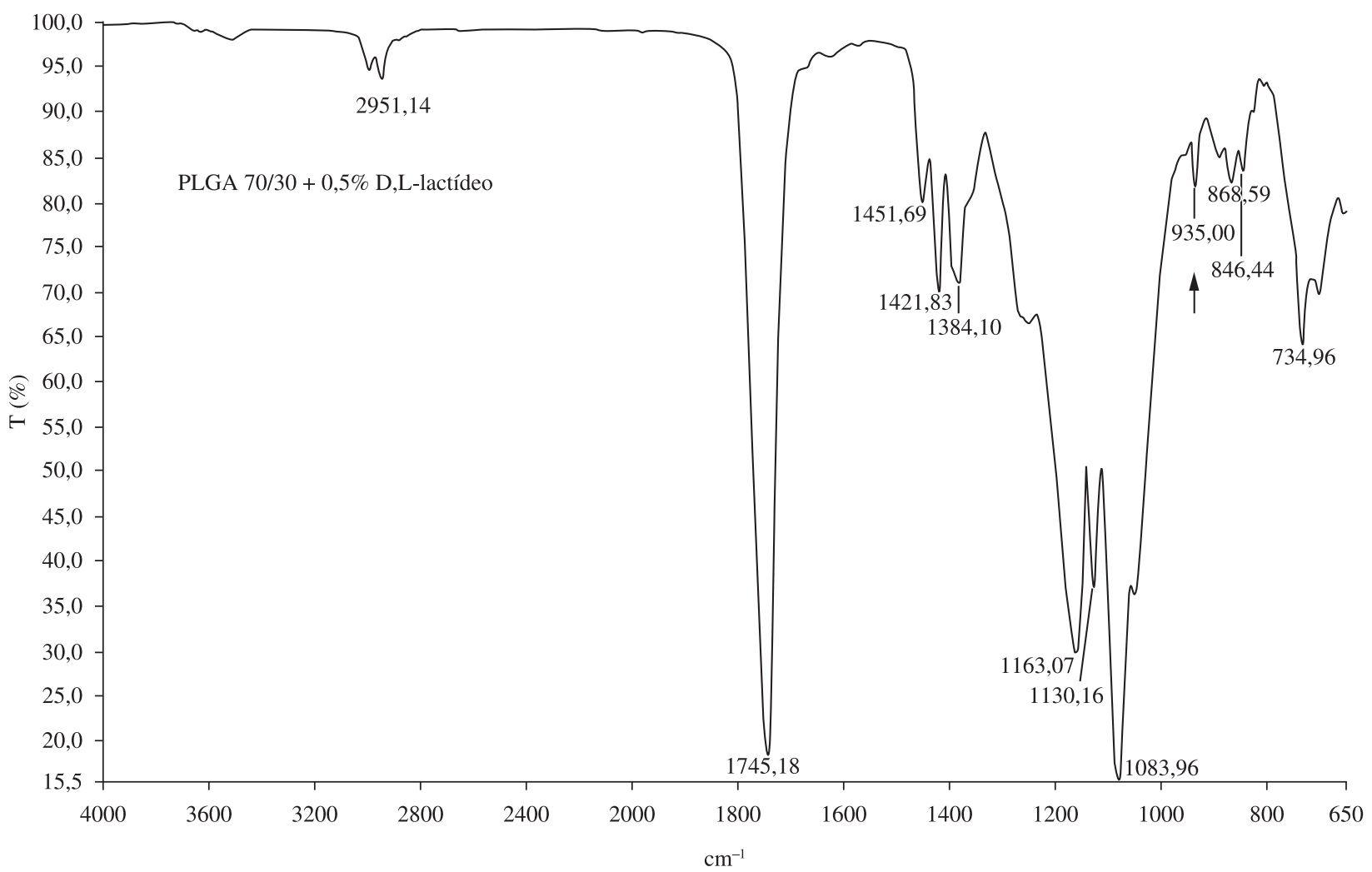

Figura 7. Espectro FTIR para a mistura de PLGA 70/30 com 0,5\% D,L-lactídeo. 


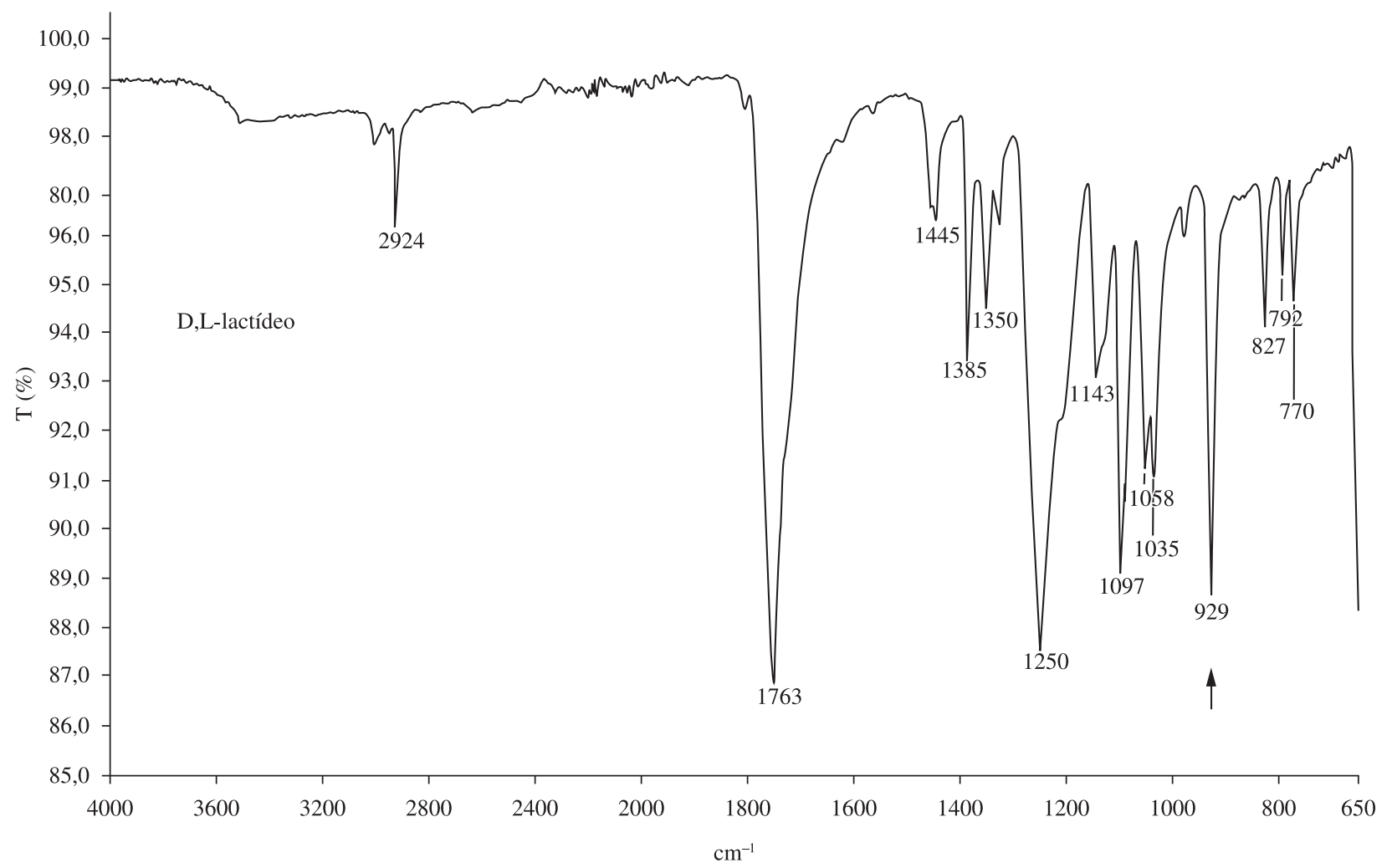

Figura 8. Espectro FTIR do monômero D,L-lactídeo.

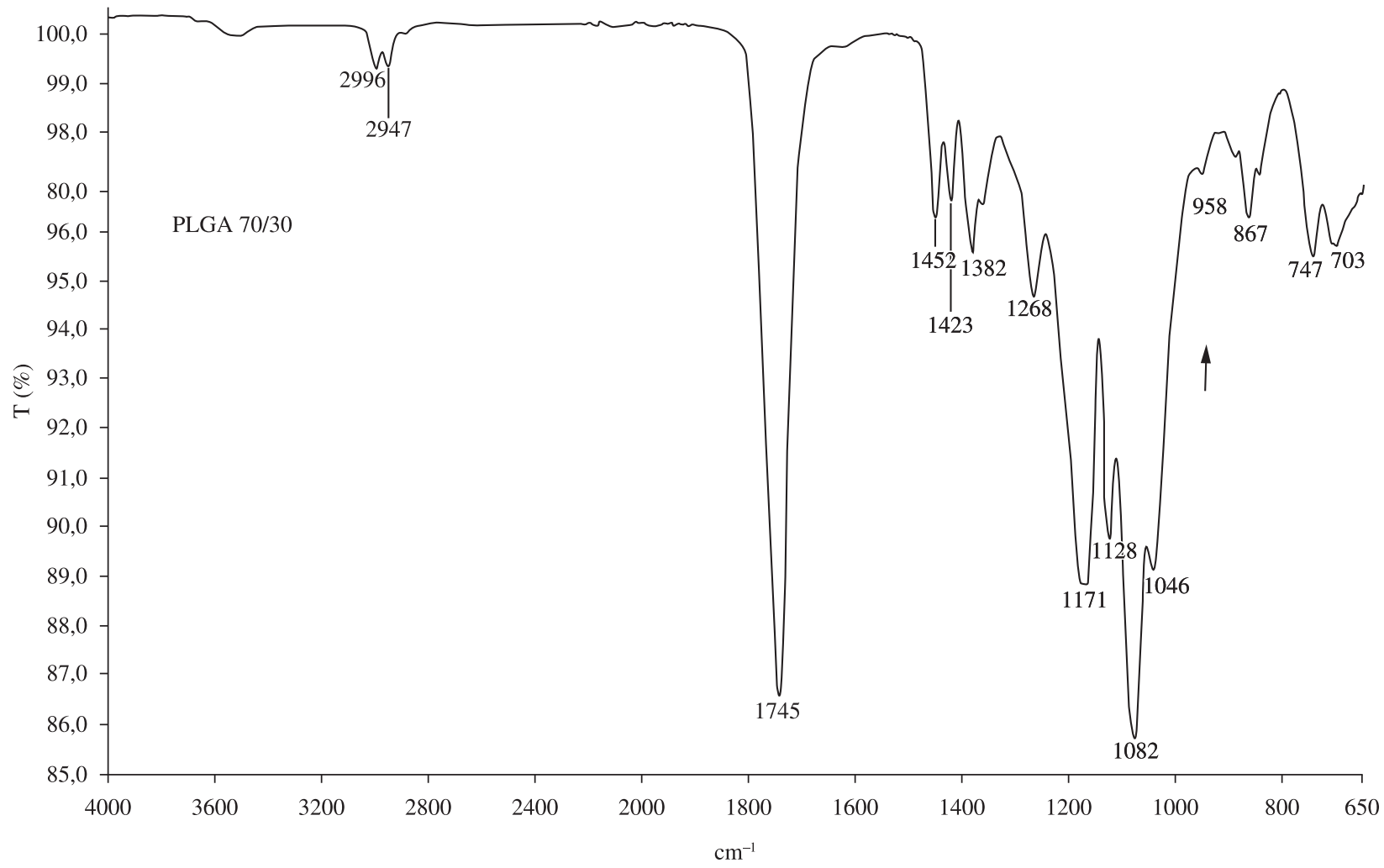

Figura 9. Espectro FTIR do PLGA 70/30 usado como base da mistura. 
possível perceber no espectro do D,L-lactídeo, Figura 8, uma banda de grande intensidade em $929 \mathrm{~cm}^{-1}$, muito próxima àquela da mistura de PLGA com $0,5 \%$ de D,L-lactídeo. Portanto, acredita-se que o monômero D,L-lactídeo não está presente nos copolímeros de PLGA sintetizados neste trabalho com uma concentração maior ou igual a $0,5 \%$.

Quanto aos espectros referentes à mistura do PLGA 70/30 com o monômero glicolídeo, não foi possível detetar qualquer alteração significativa com a adição deste monômero que permitisse realizar a mesma análise feita para o monômero D,L-lactídeo. Todos os picos de absorção que o monômero glicolídeo apresenta são sobrepostos aos do copolímero PLGA.

Acredita-se na viabilidade do emprego da análise de FTIR na pesquisa de monômeros residuais, em especial do monômero D,L-lactídeo, onde foi possível detetar alteração no espectro do copolímero com apenas $0,5 \%$ de resíduo do mesmo.

\section{Conclusões}

Com relação aos copolímeros sintetizados, estes apresentaram temperatura de transição vítrea entre 35 e $41{ }^{\circ} \mathrm{C}$ e estabilidade térmica até $240{ }^{\circ} \mathrm{C}$. A perda de massa dos copolímeros ocorreu em uma única etapa, com início entre 246 e $253^{\circ} \mathrm{C}$.

Quanto às análises por FTIR, conseguiu-se determinar nos espectros dos copolímeros sintetizados, todos os grupos funcionais de referência $\left(\mathrm{C}=\mathrm{O}, \mathrm{C}-\mathrm{O}, \mathrm{CH}_{3}, \mathrm{CH}_{2}\right.$ e $\left.\mathrm{CH}\right)$. Os espectros dos copolímeros sintetizados estão de acordo com a literatura.

Para determinar a presença de monômeros residuais nos copolímeros sintetizados, buscou-se reunir os resultados de todas as técnicas de análise empregadas na caracterização dos mesmos. A técnica por DSC mostrou que não foi detetado qualquer evento endotérmico próximo à temperatura de fusão dos monômeros. Já a termogravimetria não apresentou qualquer perda de massa significativa anterior ao início de perda de massa do copolímero, lembrando que a perda de massa para os monômeros termina bem antes do início da perda de massa do copolímero. Com relação à técnica de FTIR, pode-se inferir que o copolímero PLGA 70/30 não tem monômero D,L-lactídeo residual com concentrações iguais ou superiores a $0,5 \%$ em massa. Essas técnicas contribuíram para inferir que não havia resíduos de monômeros em todos os copolímeros sintetizados, passível de deteção por cada uma delas.

Portanto, pode-se concluir que as sínteses dos copolímeros de PLGA, por meio dessa nova rota proposta, foram realizadas com sucesso, conforme comprovado pelas análises por FTIR, DSC e TG.

\section{Agradecimentos}

Os autores agradecem o aporte financeiro da FAPEMIG, CAPES e CNPQ e Cynthia D. C. Erbetta agradece à FAPEMIG pela bolsa de mestrado concedida.

\section{Referências Bibliográficas}

1. Villanova, J. C. O.;Oréfice, R. L. \& Cunha, A. S. - Polímeros, 20, p.51 (2010). http://dx.doi.org/10.1590/S0104-14282010005000009

2. Barbanti, S. H.; Zavaglia, C. A.C. \&Duek, E. A. R. - Polímeros, 16, p.141 (2006).
3. Soares, A. Q.; Oliveira, L. F.; Rabelo, D.\& Souza, A. R. -Rev.Elet. Farmácia, 2, p.202 (2005).

4. Jain, R. A. -Biomaterials, 21, p.2475 (2000). http://dx.doi.org/10.1016/ S0142-9612(00)00115-0

5. Hans, M. L. \& Lowman, A. M. -Curr. Opin. Solid State Mater. Sci.,6, p.319 (2002). http://dx.doi.org/10.1016/S1359-0286(02)00117-1

6. Cai, Q.; Shi, G.; Bei, J. \& Wang, S. -Int. J. Pharm., 24, p.629 (2003).

7. Ratner, B. D. \& Hoffman, A. S. - "Biomaterials Science - An Introduction to Materials in Medicine", Elsevier Academic Press, Londres (1996).

8. Bendix, D. -Polym.Degrad.Stab,59, p.129 (1998). http://dx.doi. org/10.1016/S0141-3910(97)00149-3

9. Xiaoling, L. \&Haskara R. J. - "Design of controlled release drug delivery systems", MacGraw-Hill, New York (2006).

10. Gilding, D. M. \& Reed, A. M. - Polymer, 20, p.1459 (1979). http:// dx.doi.org/10.1016/0032-3861(79)90009-0

11. Lunt, J. -Polym. Degrad. Stab,59, p.145, (1998). http://dx.doi. org/10.1016/S0141-3910(97)00148-1

12. Fukuzaki, H.; Yoshida, M.; Asano M.\&Kumakura,M. - Eur. Polym. J., 25, p. 1019 (1989). http://dx.doi.org/10.1016/0014-3057(89)90131-6

13. Jéôme, C. \&Lecomte, P. -Adv. Drug Deliv. Rev., 60, p. 1056 (2008).

14. Deasy, P. B.; Finan M. P. \& M. Meegan, J. - J. Microencapsulation 6, p. 369 (1989). http://dx.doi.org/10.3109/02652048909019919

15. Chasin, M. \& Langer, R.- "Biodegradable polymers as drug delivery systems", McGraw-Hill, New York (1990).

16. Merkli, A.; Tabatabay, C.; Gurny, R. \& Heller, J. - Progress Polym.Sci., 23, p.563 (1998). http://dx.doi.org/10.1016/S00796700(97)00048-8

17. Athanasiou, K. A.; Niederauer, G. G. \&Agrawal, C. M. Biomaterials, 17, p.93 (1996). http://dx.doi.org/10.1016/01429612(96)85754-1

18. Kiremitçi-gümüsderelioglu, M. \&Deniz, G. - Turk J. Chem, 23, p.153 (1999).

19. Kaitian, X.; Kozluca, A.; Denkbas, E. B. \&Piskin, E. - Tr. J. of Chemistry, 20, p.43 (1996).

20. Jabbari, E. \&Xuezhong, E. -J. Mater. Sci.: Mat. in Medicine, 19, p.311 (2008). http://dx.doi.org/10.1007/s10856-006-0020-2

21. Kumar, V. \& Banker, G. S. -Drug Dev. Ind. Pharm., 19, p.1, (1993). http://dx.doi.org/10.3109/03639049309038760

22. Silva Junior, A. A.; Matos, J. R.; Formariz, T. P.; Rossanezi, G.; Scarpa, M. V.; Egito, E. S. T. \& Oliveira, A. G. -Int. J. Pharm.,368, p.45 (2009).

23. Lindhardt, R. - "Biodegradable polymers for controlled release of drugs", Springer-Verlag, New York (1998).

24. Colthup, N. B.; Daly L. H. \&Wiberley, S. E. - "Introduction to infrared and ramanspectroscopy", Second edition, Academic Press, New York (1975).

25. Hummel, D. - "Atlas of Polymer and Plastics Analysis",VerlagChemie $\mathrm{GmbH}$, Weinheim (2001).

26. Middleton, J. C. \& Tipton, A. J. -Med. Plastics Biomat.Mag., p.31 (1998).

Enviado: $21 / 09 / 10$

Reenviado: 07/12/10

Aceito: 03/03/11

DOI: $10.1590 /$ S0104-14282011005000063 